\title{
Influence of neural mobilization in the sympathetic slump position on the behavior of the autonomic nervous system
}

\author{
Douglas Roberto da Silva ${ }^{1 *}$, Rodrigo Alexis Lazo Osório², Adriana Barrinha Fernandes ${ }^{2}$ \\ ${ }^{1}$ Biomedical Engineering Institute, University Brasil, São Paulo, SP, Brazil. \\ ${ }^{2}$ Innovation, Technology and Education Center, Biomedical Engineering Institute, University Anhembi Morumbi, São José dos \\ Campos, SP, Brazil.
}

Abstract Introduction: The neural mobilization technique in the sympathetic slump position (NMSS) was based on the slump test, whose purpose was to directly influence the sympathetic trunk and thus provide greater analgesia by sympathetic activation and treat pain syndromes caused by peripheral sympathetic changes. Therefore, as the autonomic nervous system (ANS) is responsible for extrinsic regulation of the cardiovascular system through sympathetic and parasympathetic action, the aim of this study was to investigate the influence of the NMSS technique on the systolic and diastolic blood pressure and heart rate variability in athlete and non-athlete men. Methods: Twenty-eight subjects performed the procedure that was divided into three phases: rest; intervention and recovery, lasting 4 minutes and 30 seconds each, totaling a 13-minute and 30 seconds collection time. Results: The results showed that the NMSS technique significantly influences the action/activity of the ANS, as there was predominant sympathetic activation during the application of the technique, which was observed by the increase in systolic blood pressure, low frequency (LF), LF/HF ratio and decreased values of high frequency (HF). Conclusion: It may be concluded that the neural mobilization technique on the sympathetic slump (NMSS) significantly influences the ANS action/activity. Among the groups there was no statistically significant difference in heart rate variability. It is worth noting that patients with cardiovascular disorders may be at risk if the NMSS technique is applied, since there was an increase in SBP and sympathetic activation during its application in both groups.

Keywords Neurodynamics, Autonomic nervous system, Heart rate variability.

\section{Introduction}

The neural mobilization technique on the sympathetic slump (NMSS) was based on the slump test described by Maitland (1985) to obtain greater analgesia by sympathetic activation. The test included the following parameters: contralateral thoracic inclination and rotation; contralateral cervical inclination and posterior-anterior mobilization of the costovertebral joint to create greater stress on the sympathetic trunk due to anatomic position (Butler and Slater, 1994; Cleland and McRae, 2002; Cleland et al., 2002; Giri and Nixdorf, 2007).

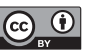

This is an Open Access article distributed under the terms of the Creative Commons Attribution License, which permits unrestricted use, distribution, and reproduction in any medium, provided the original work is properly cited.

How to cite this article: Silva DR, Osório RAL, Fernandes AB. Influence of neural mobilization in the sympathetic slump position on the behavior of the autonomic nervous system. Res Biomed Eng. 2018; 34(4):329-336. DOI: https://doi.org/10.1590/24464740.180037

*Corresponding author: Biomedical Engineering Institute, University Brasil, Rua Carolina Fonseca, 584, Itaquera, CEP 08230-030, São Paulo, SP, Brazil. E-mail: 44douglas44@gmail.com Received: 18 May 2018 / Accepted: 13 November 2018
Due to its direct influence on the sympathetic trunk, the NMSS technique can be beneficial for treating painful syndromes caused by sympathetic peripheral changes, as recent evidence suggests that increased stimulation of the sympathetic nervous system (SNS) caused by compression, trunk distortion or stretches, ganglia or connecting sympathetic branch may be related to chronic pain involving symptoms of allodynia, trophic, vasomotor and sudomotor changes (Blumberg et al., 1997; Butler and Slater, 1994; Carlson and Watson, 1998; Giri and Nixdorf, 2007).

However, the autonomic nervous system (ANS) plays a prominent role in controlling the balance of cardiovascular functions (Sata et al., 2018; Seravalle et al., 2018; Silveira et al., 2012). The maintenance of pressure levels within a range of normality depends on variations in cardiac output or peripheral resistance or both. Among the most important peripheral sensors in this modulation, we describe the role of arterial mechanoreceptors and chemoreceptors and cardiopulmonary receptors in different pathophysiological situations. For instance, a rise in blood pressure activates baroreceptors that inhibit the tonic activity of sympathetic preganglionic neurons in the spinal cord. In parallel, increased pressure stimulates the activity of 
the parasympathetic preganglionic neurons in the dorsal motor nucleus of the vagus and in the ambiguous nucleus that influence the heart rate. The carotid chemoreceptors also have some influence, but this is a less important impulse than that derived from the baroreceptors. As a result of this shift in the balance of sympathetic and parasympathetic activity, the noradrenergic stimulatory effects of postganglionic sympathetic innervation on the cardiac pacemaker and cardiac musculature are reduced (an effect aided by decreased catecholamine production of the adrenal medulla and decreased vasoconstriction effects of sympathetic innervation on peripheral blood vessels). At the same time, activation of the heart's parasympathetic cholinergic innervation decreases the rate of cardiac pacemaker discharge at the sinoatrial node and delays the ventricular conduction system. These parasympathetic influences are mediated by an extensive series of parasympathetic ganglia in and near the heart that release acetylcholine into cardiac pacemaker cells and cardiac muscle fibers. As a result of this combination of sympathetic and parasympathetic effects, heart rate and the effectiveness of atrial and ventricular contraction of the myocardium are reduced and the peripheral arterioles dilate, thereby lowering blood pressure (Chapleau et al., 1989; Di Rienzo et al., 2009; Irigoyen et al., 2001; Lopes et al., 2000; Seravalle et al., 2018). Therefore the ANS branches are responsible for extrinsic regulation and work together through sympathetic and parasympathetic action, modifying the frequency of heart beats to adjust blood pressure (BP). The resulting effect of these autonomic influences is called heart rate variability (HRV) (Alderman and Olson, 2014; Hasan, 2013; Kawaguchi et al., 2007; Silveira et al., 2012).

The measurement of $\mathrm{HRV}$ is a noninvasive technique used to investigate ANS functioning related to sympathovagal balance (Borell et al, 2007; Casonatto et al., 2011; Vieira et al., 2012). The measurement of HRV can be done mainly in time and frequency domain (spectral analysis), of which the frequency domain is more frequently chosen to assess ANS functioning in individuals at rest (Corazza et al., 2014; Hodges et al., 2018; Kawaguchi et al., 2007; Vanderlei et al., 2009; Vieira et al., 2012; Rassi, 2018; Wazen et al., 2018). The HRV is based on three spectral components: high frequency (HF) - ranging from 0.15 to $0.4 \mathrm{~Hz}$, which corresponds to the respiratory modulation and indicates the performance of the vagus (parasympathetic) nerve on the heart rate; low frequency (LF) - ranging from 0.04 to $0.15 \mathrm{~Hz}$, the result of the vagus nerve and sympathetic action on the heart, with sympathetic predominance; very low frequency (VLF) - ranging from 0.003 to $0.04 \mathrm{~Hz}$, less frequently used rates whose physiological explanation is not well established and the LF/HF ratio that characterizes the cardiac sympathetic-vagal balance (Borell et al., 2007; Chua et al., 2008; Goldstein et al., 2011; Grassi et al.,
2012; Malliani, 1999; McCraty and Shaffer, 2015; Task..., 1996; Vanderlei et al., 2009).

The hypothesis of this study is to show evidence about the central influences caused by the application of the neural mobilization technique on the sympathetic slump in men with different physical conditions, since sports practice can influence the ANS activity. In addition to contributing to the understanding and establishment of criteria for its application in people with some type of cardiovascular injury. Given the above, the aim of the study was to verify the influence of the NMSS technique on systolic and diastolic blood pressure and heart rate variability in men (athletes and non-athletes).

\section{Methods}

\section{Subjects}

This is a clinical analytical, prospective, cross-sectional study, in which the same individual was control. The 28 healthy male volunteers were divided into two experimental groups (NAMG - non-athlete men and AMG - athlete men). The AMG group consisted of triathlon athletes who performed a training routine of five times a week, involving running, swimming e cycling. Athlete and non-athlete men who signed the free and informed consent were included in the study. Volunteers who had musculoskeletal and/or neurological injuries, rest heart rate below 60 and above 100 beats per minute, systolic blood pressure at rest below 90 and above $140 \mathrm{mmHg}$, cardiovascular abnormality, and those who could not reach $25 \mathrm{~cm}$ below the knee in the standing flexion test and positive neural tension for the Slump test, conditions that may cause discomfort during the Slump position. Furthermore, volunteers who were smokers also were excluded.

\section{Experimental procedures}

The survey was conducted in a controlled-temperature room between $23^{\circ} \mathrm{C}$ and $25^{\circ} \mathrm{C}$. The procedures were performed between April and June 2014 from 10:00 to 11:00 in the morning.

Volunteers were instructed not to ingest coffee, alcohol or other beverages that could stimulate or inhibit ANS activity two hours before the procedure. For posterior-anterior mobilization (PA), the $9^{\text {th }}$ costovertebral joint was marked with a pen before the first phase. According to Nathan (1987), the sympathetic ganglion immediately crosses the T9-T10 costovertebral joints. The procedure was divided into three phases: rest; intervention and recovery, lasting 4 minutes and 30 seconds each, totaling a 13 -minute and 30 seconds collection time. During each phase, the following procedures were performed:

- Rest: volunteer sat on the plinth with legs bent over the plinth; 
- Intervention: application of the NMSS technique on the $9^{\text {th }}$ costovertebral joint with volunteer sitting in the sympathetic slump position. The technique was applied continuously in three sets of one minute, with a thirty-second interval between them;

- Recovery: follow-up phase of the autonomic nervous system response after stimulation, volunteer in the same position as the rest phase;

\section{Protocol for data acquisition and processing}

To collect PA, the volunteer wore the Premium ${ }^{\circledR}$ digital blood pressure device on the right wrist, according to manufacturer's guidelines. The volunteer was instructed to place his right hand on his left shoulder so that the device was at heart height and the volunteer in the position of their respective collection phases. Collection was held at the beginning of the rest phase, early recovery phase, and final recovery phase. The Polar ${ }^{\circledR}$ heart monitor RS800CX and Polar ${ }^{\circledR}$ WearLink sensor were used for heat rate (HR) data collection. We chose the Polar ${ }^{\circledR}$ heart monitor RS800CX instead of the electrocardiogram (ECG) because previous studies have shown that both have equivalent scientific value, and therefore it could be used for scientific research (Borell et al., 2007; Essner et al., 2013; Krygier et al., 2013; Quintana et al., 2013; Wallen et al., 2012).

The HR data collection was recorded and digitalized at $1000 \mathrm{~Hz}$ with temporal resolution of 1 -ms for each R-R interval and imported into the Polar ${ }^{\circledR}$ cardiac monitor RS800CX through the Polar ${ }^{\circledR}$ WearLink. In addition, the data was transmitted via infrared sensor through the Irda-USB interface to a notebook containing the Polar ${ }^{\circledR}$ ProTrainer 5 software, a software for automatic error correction and computing of HRV to obtain the data of evolution of the signal power at different levels of decomposition: LF, HF and LF/HF. This program is able to identify occasional ectopic beats (irregularities in heart rhythm involving extra systoles and consecutive compensatory pause) and to replace these with interpolated adjacent R-R interval values (Wazen et al., 2018). Power Spectral Density is calculated using autoregressive modeling, and the spectral power in the selected area is calculated over various frequency bands: - total power $\left(\mathrm{ms}^{2}\right)$ : total spectral power over frequencies between DC (average value) and $0.40 \mathrm{~Hz}$; VLF $\left(\mathrm{ms}^{2}\right)$ : spectral power of the R-R intervals in the selected area in the Very Low-Frequency range between DC and $0.040 \mathrm{~Hz}$; $\mathrm{LF}\left(\mathrm{ms}^{2}\right)$ : Spectral power in the Low-Frequency range between 0.04 and $0.15 \mathrm{~Hz} ; \mathrm{HF}\left(\mathrm{ms}^{2}\right)$ : Spectral power in the High-Frequency range between 0.15 and $0.40 \mathrm{~Hz}$. This frequency band usually includes the respiratory frequency; $\mathrm{LF} / \mathrm{HF}$ (\%): Relation of low-frequency power to high-frequency power (Polar, 2018).

\section{Statistical analysis}

The ANOVA test followed by Tukey's post-test at a 5\% significance level $(\mathrm{p}<0.05)$ were used for statistical assessment. The INSTAT3 software was used for statistical analysis.

\section{Results}

The sample consisted of 28 healthy male volunteers divided into the two following groups: NAMG and AMG (Table 1).

Tables 2 and 3 shows the data on HRV and BP in the NAMG an AMG groups at rest, intervention and recovery phases.

Table 1. Characterization of sample groups and anthropometric data of volunteers (mean and standard deviation).

\begin{tabular}{ccc}
\hline & Non-Athlete Men Group & Athlete Men Group \\
\hline Number & 15 & 13 \\
Gender & Men & Men \\
Age & $31.6 \pm 2.5$ & $31.3 \pm 2.5$ \\
Height $(\mathrm{cm})$ & $177.1 \pm 4.7$ & $177.5 \pm 4.9$ \\
Weight $(\mathrm{kg})$ & $81.2 \pm 7.7$ & $67.9 \pm 5.8$ \\
Body Mass Index $\left(\mathrm{kg} / \mathrm{m}^{2}\right)$ & $25.8 \pm 1.9$ & $21.5 \pm 0.8$ \\
Physical activity & Non-athletes & Athletes* \\
\hline
\end{tabular}

*Triathlon athletes.

Table 2. Mean values, standard error of LF (low frequency), HF (high frequency), LF/HF (LF/HF ratio), SBP (systolic blood pressure) and DBP (diastolic blood pressure) at rest, intervention and recovery phases in the Non-Athlete Men Group (NAMG).

\begin{tabular}{cccc}
\hline Group NAMG & Rest & Intervention & Recovery \\
\hline LF $\left(\mathrm{ms}^{2}\right)$ & $1363.5 \pm 378.6$ & $2896.8^{*} \pm 813.6$ & $1808.6^{\#} \pm 416.3$ \\
HF $\left(\mathrm{ms}^{2}\right)$ & $842.52 \pm 174.7$ & $468.23^{*} \pm 128.9$ & $629.66 \pm 150.9$ \\
LF/HF (\%) & $1.5 \pm 0.13$ & $8.0^{*} \pm 1.9$ & $3.5^{\#} \pm 0.7$ \\
SBP (mmHg) & $129 \pm 2.9$ & $141^{*} \pm 2.9$ & $121^{\#} \pm 3.1$ \\
DBP (mmHg) & $83 \pm 0.9$ & $86 \pm 1.3$ & $78^{* *} \pm 1.7$ \\
\hline
\end{tabular}

* Significant difference compared to the rest phase $(\mathrm{p}<0.05)$; \# Significant difference compared to the intervention phase ( $<<0.05)$. 
Table 3. Mean values followed by standard error of LF (low frequency), HF (high frequency), LF/HF (LF/HF ratio), SBP (systolic blood pressure) and DBP (diastolic blood pressure) at rest, intervention and recovery phases in the Athlete Men Group (AMG).

\begin{tabular}{cccc}
\hline Group AMG & Rest & Intervention & Recovery \\
\hline LF $\left(\mathrm{ms}^{2}\right)$ & $1064.0 \pm 140.8$ & $2554.0^{*} \pm 459.5$ & $1845.3^{* \#} \pm 344.1$ \\
HF $\left(\mathrm{ms}^{2}\right)$ & $868.81 \pm 122.1$ & $460.80^{*} \pm 94.1$ & $534.57^{*} \pm 66.8$ \\
LF/HF (\%) & $1.3 \pm 0.2$ & $10.4^{*} \pm 3.2$ & $4.2^{\#} \pm 0.9$ \\
SBP $(\mathrm{mmHg})$ & $124 \pm 3.6$ & $138^{*} \pm 3.2$ & $126^{\#} \pm 3.1$ \\
DBP $(\mathrm{mmHg})$ & $79 \pm 1.9$ & $82 \pm 6.6$ & $80 \pm 1.6$ \\
\hline
\end{tabular}

* Significant difference compared to the rest phase $(\mathrm{p}<0.05)$; \# Significant difference compared to the intervention phase $(\mathrm{p}<0.05)$.

Comparing the LF waves in the NAMG and AMG groups between all phases, we noticed a significant increase in the intervention phase when compared to the rest phase, while there was a statistically significant decrease between intervention and recovery phases. In addition, in the AMG group noted increase in the rest phase when compared to the recovery phase.

In the HF waves, we noted a statistically significant decrease when compared with the intervention and rest phase in both groups. The same occurred when the HF values of the recovery phase were compared to the rest phase, however, only in the AMG group.

As for the LF/HF ratio, a significant increase in the intervention phase was found when compared to the rest phase, while a statistically significant decrease occurred between the intervention and recovery phases in the NAMG e AMG groups.

In the NAMG group, in the analysis of systolic blood pressure (SBP), we found a significant increase in the intervention phase when compared to the rest phase. However, when comparing intervention and recovery phases, no statistically significant reduction in SBP was found. When comparing the diastolic blood pressure values (DBP), a statistically significant reduction was observed in the recovery phase when compared to the rest phase. The same was observed when the recovery phase was compared to the intervention phase.

When comparing the SBP values in the AMG analysis, a significant increase was found when the intervention phase was compared to the rest phase. As for the intervention and recovery phase, no statistically significant decrease was found in SBP. As for DBP, no significant difference was found at the different phases of the procedure.

Figure 1 shows the data in percentage related to the sympathovagal balance and LF/HF ratio in the groups. A significant increase was found when the intervention phase was compared to the rest phase, while a statistically significant decrease was found between intervention and recovery phases. Among the groups there was no difference.

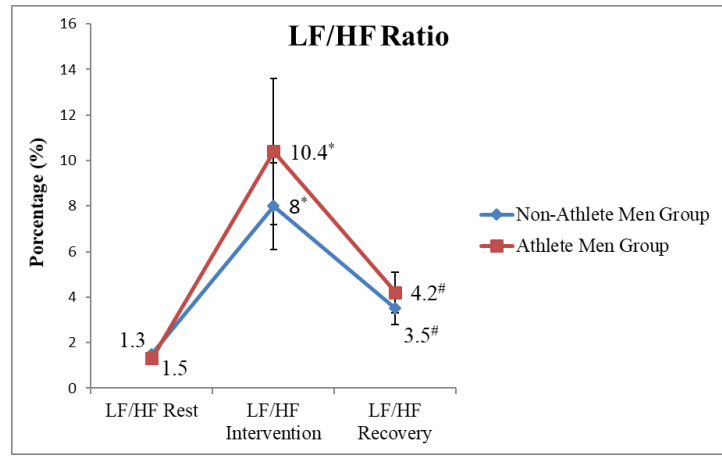

Figure 1. Mean values in percentage of sympathovagal balance (LF/HF) at rest, intervention and recovery phases in the groups. *Significant difference compared to the rest phase $(\mathrm{p}<0.05)$; \#Significant difference compared to the intervention phase $(\mathrm{p}<0.05)$.

\section{Discussion}

In the present study we found that ANS activation occurred after the application of the sympathetic slump technique in both study groups, a fact that is characterized by the increase in DBP, LF, LF/HF ratio and decrease in HF during the intervention phase.

In the literature, several studies have been conducted to analyze the effect of neural and spinal mobilization on the peripheral sympathetic nervous system and only a few analyze the central effect. After the application of the cervical lateral glide technique, Vicenzino et al. (1998) observed central sympathetic activation due to changes in the cardiovascular and respiratory system. These findings were also found by McGuiness et al. (1997) during the application of P-A spinal mobilization, corroborating the findings of the present study. However, no studies have compared the main effects in volunteers with different cardiovascular conditioning, that is, in athletes and sedentary individuals, since the autonomic regulation response is different depending on sport practice. According to Raczak et al. (2006), the chronic effect obtained by regular physical exercise improves autonomic modulation of the cardiovascular system by increasing heart rate variability and promoting greater vagal predominance. 
With regard to the peripheral effect, Petersen et al. (1993) conducted studies by applying a P-A central mobilization on C5 ( $5^{\text {th }}$ cervical vertebra); Cleland et al. (2002), Slater et al. (1994) applied NMSS; Sterling et al. (2001) applied the P-A lateral glide technique on C5/C6 (5th and 6th cervical vertebrae); Perry and Green (2008) used the left unilateral P-A mobilization on L4/L5 ( $4^{\text {th }}$ and $5^{\text {th }}$ lumbar vertebra) and Jowsey and Perry (2010) mobilized the T4 vertebra (fourth thoracic vertebra) in P-A. After the application of the technique, all the above-mentioned studies found effects of sudomotor and/or vasomotor peripheral sympathetic activation when compared with the control group. With regard to mobilization, changes in rhythm oscillation and time may interfere with the response intensity of ANS, in which an increase in the frequency of oscillation and application time can cause increased autonomic response (Chiu and Wright, 1996; Vicenzino et al., 1994).

As for the results obtained in our study on sympathetic and parasympathetic variation at rest, intervention (application of the NMSS technique) and recovery phases, our findings corroborate Silveira et al. (2012) that indicate that the mechanisms that control the responses of HR are influenced by the sympathetic and parasympathetic branch of the autonomic nervous system and there is a predominance of the parasympathetic branch at rest, whereas with increasing exercise intensity it is inhibited, becoming reduced and returning to the rates before exercise, close to those observed at rest. According to the author, at the initial moment of the exercise, HF increases in response to vagal inhibition reflex and a joint action of the ANS branches occurs in the recovery phase in the search for sympathovagal balance. In the present study, we found that there is a predominance of the parasympathetic branch in the two groups assessed at rest. However, with the application of NMSS technique, there is an increase in sympathetic activity and a tendency to return to rest levels after the application of the technique (recovery phase). By contrast, the LF waves, an indicator of sympathetic activation, reduced at the rest phase in the NAMG and AMG groups, rose during the application of NMSS technique, and quickly reduced in the recovery phase.

Slater et al. (1994) found increased sympathetic activity in asymptomatic individuals when assessing the increase in skin conductivity and reduction in skin temperature after the application of the sympathetic slump, corroborating the findings of sympathetic activation in the present study.

A valid hypothesis is that the sympathetic effect of the NMSS technique may be related to the inclinations associated with the slump position. Shacklock (2007), describing studies conducted by Alf Breig, explains that the flexion caused by the seated position (slump), lateral flexion and contralateral rotation impose great strain on the nervous system due to joint mobilization and the slump test. Kingston et al. (2014) reported in a systematic review of studies that there is a sympathetic excitatory response to spinal mobilizations on the spine irrespective of the mobilized segment.

In another study, Cleland and McRae (2002) showed the effectiveness of the NMSS technique for pain control but assessed sympathetic activation for vasomotor and sudomotor changes. According to Lovick (1991), one of the analgesic possibilities of the technique is based on anatomical location; analgesia would be performed by co-activation of spinal neurons leading to inhibition of sensory neurons (nociceptive afferents) and facilitation of sympathetic neural activation. Another theory for analgesia found and cited by some authors is the stimulation of the dorsal periaqueductal gray matter with norepinephrine as a neurotransmitter that is released when there is sympathetic stimulation, which was found in our study after applying the technique (Evans, 2002; Lovick, 1985).

With regard to the findings of SBP and DBP, an increase in these parameters was found in both groups during the application of the technique. This finding is pointed out in the systematic review study by Kingston et al. (2014) who affirm that there is positive sympathoexcitatory response in skin conductance, respiratory rate, blood pressure and heart rate irrespective of mobilized segments.

As for physical activity, at any intensity, Middleton and De Vito (2005) suggests that this can significantly influence the action/activity of ANS. In fact, it was evident in our study because the HRV was higher during NMSS in the AMG group than the one observed in the NAMG group. These results are in agreement with those of Kawaguchi et al. (2007) and Vanderlei et al. (2009), who reported in their studies that physical training increases physiological capacity of the cardiovascular system. These findings can be observed due to the higher HRV readings; the higher the HRV, the better is the adaptation to changes and/or stimuli from the external environment.

When we compared the SBP and DBP values between the groups, we found that these parameters varied greatly in athletes when comparing the rest phase and recovery. The same was not observed for the non-athlete volunteers, suggesting that these individuals need more time to adapt to the applied stimulus. These results corroborate Laterza et al. (2007) and Vanderlei et al. (2009), who reported that PA variation can serve as an important health parameter as well as an indicator of physical conditioning of the individual. In non-sedentary individuals the variation between rest and after stimulation were closer, showing better adaptation to the stimulus, while variation between rest 
and after stimulation in sedentary individuals was farther apart, revealing slower/less efficient adaptation. These results suggest that baroreflex sensitivity is a variable that is effectively influenced by physical training, being able to differentiate precisely the physical conditioning of individuals.

If the ANS can influence the cardiovascular system by increasing HR and BP (Alla et al., 2000; Polito and Farinatti, 2003), people with cardiovascular changes may be at risk if the NMSS technique is applied due to an increase in sympathetic activation was found in all groups.

It may be concluded that the neural mobilization technique on the sympathetic slump (NMSS) significantly influences the ANS action/activity. There is predominant sympathetic activation during the application of the technique, which could be observed by the increase in the $\mathrm{SBP}$ values, $\mathrm{LF}$, ratio $\mathrm{LF} / \mathrm{HF}$ and reduction in $\mathrm{HF}$ values.

However, in the AMG group during recovery, the SBP values returned to initial values more quickly. Moreover, the DBP levels showed no change, suggesting that the greater the fitness of the patient, the better is ANS adaptation when implementing the NMSS technique. It is worth noting that patients with cardiovascular disorders may be at risk if the NMSS technique is applied, since there was an increase in SBP and sympathetic activation during its application in all groups. Therefore, further studies should be conducted to confirm our hypothesis.

\section{References}

Alderman BL, Olson RL. The relation of aerobic fitness to cognitive control and heart rate variability: a neurovisceral integration study. Biol Psychol. 2014; 99:26-33. http://dx.doi. org/10.1016/j.biopsycho.2014.02.007. PMid:24560874.

Alla F, Briançon S, Juillière Y, Mertes P-M, Villemot J-P, Zannad F. Differential clinical prognostic classifications in dilated and ischemic advanced heart failure: the EPICAL study. Am Heart J. 2000; 139(5):895-904. http://dx.doi.org/10.1016/ S0002-8703(00)90023-1. PMid:10783225.

Blumberg H, Hoffmann U, Mohadjer M, Scheremet R. Sympathetic nervous system and pain: a clinical re-appraisal. Behav Brain Sci. 1997; 20(3):426-34, discussion 435-513. http:// dx.doi.org/10.1017/S0140525X97271487. PMid:10097005.

Borell EV, Langbein J, Després L, Hansen S, Leterrier C, Marchant-Forde J. et al. Heart rate variability as a measure of autonomic regulation of cardiac activity for assessing stress and welfare in farm animals. Physiol Behav. 2007; 92(3):293-316. http://dx.doi.org/10.1016/j.physbeh.2007.01.007.

Butler DS, Slater H. Neural injury in the thoracic spine: a conceptual basis for manual therapy. In: Grant R, editor. Physical therapy of the cervical and thoracic spines. 2nd ed. New York: Churchill Livingstone; 1994. p. 313-38.

Carlson LK, Watson HK. Treatment of reflex sympathetic dystrophy using the stress-loading program. J Hand Ther. 1998; 1(4):149-53. http://dx.doi.org/10.1016/S0894-1130(88)80022-X.
Casonatto J, Tinucci T, Dourado AC, Polito M. Cardiovascular and autonomic responses after exercise sessions with different intensities and durations. Clinics (Sao Paulo). 2011; 66(3):4538. http://dx.doi.org/10.1590/S1807-59322011000300016. PMid:21552672.

Chapleau MW, Hajduczok G, Abboud FM. Peripheral and central mechanisms of baroreflex resetting. Clin Exp Pharmacol Physiol Suppl. 1989; 15(s15):31-43. http://dx.doi. org/10.1111/j.1440-1681.1989.tb02994.x. PMid:2680188.

Chiu TW, Wright A. To compare the effects of different rates of application of a cervical mobilisation technique on sympathetic outflow to the upper limb in normal subjects. Man Ther. 1996; 1(4):198-203. http://dx.doi.org/10.1054/ math.1996.0269. PMid:11440508.

Chua KC, Chandran V, Acharya UR, Lim CM. Cardiac state diagnosis using higher order spectra of heart rate variability. J Med Eng Technol. 2008; 32(2):145-55. http://dx.doi. org/10.1080/03091900601050862. PMid:18297505.

Cleland J, Durall C, Scott S. Effects of slump long sitting on peripheral sudomotor and vasomotor function: a pilot study. J Manual Manip Ther. 2002; 10(2):67-75. http://dx.doi. org/10.1179/106698102790819292.

Cleland J, McRae M. Complex regional pain syndrome I: management through the use of vertebral and sympathetic trunk mobilization. J Manual Manip Ther. 2002; 10(4):188-99. http://dx.doi.org/10.1179/106698102790819067.

Corazza I, Barletta G, Guaraldi P, Cecere A, Calandra-Buonaura G, Altini E, Zannoli R, Cortelli P. et al. A new integrated instrumental approach to autonomic nervous system assessment. Comput Methods Programs Biomed. 2014; 117(2):267-76. http://dx.doi.org/10.1016/j.cmpb.2014.08.002. PMid:25168777.

Di Rienzo M, Parati A, Radaelli A, Castiglioni P. Baroreflex contribution to blood pressure and heart rate oscillations: time scales, time-variant characteristics and nonlinearities Phil Trans R Soc A. 2009;367(1892):1301-18. http://dx.doi. org/10.1098/rsta.2008.0274. PMid:19324710.

Essner A, Sjostromc R, Ahlgrenb E, Lindmark B. Validity and reliability of Polar ${ }^{\circledR}$ RS800CX heart rate monitor, measuring heart rate in dogs during standing position and at trot on a treadmill. Physiol Behav. 2013; 114-115:1-5. http://dx.doi. org/10.1016/j.physbeh.2013.03.002.

Evans DW. Mechanisms and effects of spinal high-velocity, low-amplitude thrust manipulation: previous theories. J Manipulative Physiol Ther. 2002; 25(4):251-62. http://dx.doi. org/10.1067/mmt.2002.123166. PMid:12021744.

Giri S, Nixdorf D. Sympathetically maintained pain presenting first as temporomandibular disorder, then as parotid dysfunction. Tex Dent J. 2007; 124(8):748-52. PMid:17867545.

Goldstein DS, Bentho O, Park MY, Sharabi Y. LF power of heart rate variability is not a measure of cardiac sympathetic tone but may be a measure of modulation of cardiac autonomic outflows by baroreflexes. Exp Physiol. 2011; 96(12):1255-61. http:// dx.doi.org/10.1113/expphysiol.2010.056259. PMid:21890520.

Grassi G, Seravalle G, Brambilla G, Mancia G. The sympathetic nervous system and new nonpharmacologic approaches to treating hypertension: a focus on renal denervation. Can 
J Cardiol. 2012; 28(3):311-7. http://dx.doi.org/10.1016/j. cjca.2011.11.005. PMid:22244774.

Hasan W. Autonomic cardiac innervation. Organogenesis. 2013; 99(3):176-93. http://dx.doi.org/10.4161/org.24892.

Hodges GJ, Kiviniemi AM, Mallette MM, Klentrou P, Falk B, Cheung SS. Effect of passive heat exposure on cardiac autonomic function in healthy children. Eur J Appl Physiol. 2018; 118(10):2233-40. http://dx.doi.org/10.1007/s00421018-3957-1. PMid:30069604.

Irigoyen MC, Consolim-Colombo FM, Krieger EM. Cardiovascular control: role of the sympathetic nervous system. Rev Bras Hipertens. 2001; 8:55-62.

Jowsey P, Perry J. Sympathetic nervous system effects in the hands following a grade III póstero-anterior rotatory mobilization technique applied to T4: a randomised, placebo-controlled trial. Man Ther. 2010; 15(3):248-53. http://dx.doi.org/10.1016/j. math.2009.12.008. PMid:20093065.

Kawaguchi LYA, Nascimento ACP, Lima MS, Frigo L, Paula AR Jr, Tierra-Criollo CJ, Lopes-Martins RAB. Characterization of heart rate variability and baroreflex sensitivity in sedentary individuals and male athletes. Rev Bras Med Esporte. 2007; 13(4):231-6. http://dx.doi.org/10.1590/S1517-86922007000400004.

Kingston L, Claydon L, Tumilty S. The effects of spinal mobilizations on the sympathetic nervous system: a systematic review. Manual Therapy. 2014; 19:281-7. http://dx.doi. org/10.1016/j.math.2014.04.004.

Krygier JR, Heathers JAJ, Shahrestani S, Abbott M, Gross JJ, Kemp AH. Mindfulness meditation, well-being, and heart rate variability: a preliminary investigation into the impact of intensive Vipassana meditation. Int J Psychophysiol. 2013; 89(3):305-13. http://dx.doi.org/10.1016/j.ijpsycho.2013.06.017. PMid:23797150.

Laterza MC, Rondon MUPB, Negrão CE. The anti-hypertensive effect of exercise. Rev Brasi Hipertensão. 2007; 14(2):104-11.

Lopes HF, Silva HB, Consolim-Colombo FM, Barreto JA Fo, Riccio GMG, Giorgi DMA, Krieger EM. Autonomic abnormalities demonstrable in young normotensive subjects who are children of hypertensive parents. Braz J Med Biol Res. 2000; 33:51-4. http://dx.doi.org/10.1590/S0100-879X2000000100007.

Lovick TA. Interactions between descending pathways from the dorsal and ventrolateral periaqueductal gray matter in the rat. In: Depaulis A, Bandler R, editors. The midbrain periaqueductal gray matter. New York: Plenum Press; 1991. p. 101-34. http://dx.doi.org/10.1007/978-1-4615-3302-3_7.

Lovick TA. Ventrolateral medullary lesions block the antinociceptive and cardiovascular responses elicited by stimulating the dorsal periaqueductal grey matter in rats. Pain. 1985; 21(3):241-52. http://dx.doi.org/10.1016/03043959(85)90088-0. PMid:3991230.

Maitland G. The slump test: examination and treatment. Aust J Physiother. 1985; 31(6):215-9. http://dx.doi.org/10.1016/ S0004-9514(14)60634-6. PMid:25026106.

Malliani A. The pattern of sympathovagal balance explored in the frequency domain. News Physiol Sci. 1999; 14:111-7. PMid:11390833.
McCraty R, Shaffer F. Heart rate variability: new perspectives on physiological mechanisms, assessment of self-regulatory capacity, and health risk. Glob Adv Health Med. 2015; 4(1):4661. http://dx.doi.org/10.7453/gahmj.2014.073. PMid:25694852.

McGuiness J, Vicenzino B, Wright A. Influence of a cervical mobilization technique on respiratory and cardiovascular function. Man Ther. 1997; 2(4):216-20. http://dx.doi.org/10.1054/ math.1997.0302. PMid:11440535.

Middleton N, De Vito G. Cardiovascular autonomic control in endurance-trained and sedentary young women. Clin Physiol Funct Imaging. 2005; 25(2):83-9. http://dx.doi.org/10.1111/ j.1475-097X.2004.00594.x. PMid:15725306.

Nathan H. Osteophytes on the spine compressing the sympathetic trunk and splanchnic nerves in the thorax. Spine. 1987; 12(6):527-32. http://dx.doi.org/10.1097/00007632-19870700000003. PMid:3660077.

Perry J, Green A. An investigation into the effects of a unilaterally applied lumbar mobilisation technique on peripheral sympathetic nervous system activity in the lower limbs. Man Ther. 2008; 13(6):492-9. http://dx.doi.org/10.1016/j.math.2007.05.015. PMid:17643340.

Petersen N, Vicenzino B, Wright A. The effects of a cervical mobilisation technique on sympathetic outflow to the upper limb in normal subjects. Physiother Theory Pract. 1993; 9(3):149-56. http://dx.doi.org/10.3109/09593989309047454.

Polar. Global: support polar - selection Info Analysis for R-R data [Internet]. 2018 [cited 2018 Nov 5]. Available from: https://support.polar.com/en/support/Selection_Info_Analysis for_R_R_data?product_id $=38638$ \&category $=$ faqs

Polito MD, Farinatti PTV. Heart-rate, blood pressure, and rate pressure product during resistive exercises: a review of the literature. Rev Port Cienc Desporto. 2003; 3(1):79-91. http:// dx.doi.org/10.5628/rpcd.03.01.79.

Quintana DS, Guastella AJ, McGregor IS, Hickie IB, Kemp $\mathrm{AH}$. Heart rate variability predicts alcohol craving in alcohol dependent outpatients: Further evidence for HRV as a psychophysiological marker of self-regulation. Drug Alcohol Depend. 2013; 132(1-2):395-8. http://dx.doi.org/10.1016/j. drugalcdep.2013.02.025. PMid:23601925.

Raczak G, Daniłowicz-Szymanowicz L, Kobuszewska-Chwirot M, Ratkowski W, Figura-Chmielewska M, Szwoch M. Longterm exercise training improves autonomic nervous system profile in professional runners. Kardiol Pol. 2006; 64(2):13540, discussion 141-2. PMid:16502362.

Rassi A Jr. Understanding better the measures of variability analysis [Internet]. 2018 [cited 2018 June 10]. Available from: http://www.cardios.com.br/noticias_detalhes.asp?idN oticia $=331 \&$ IdSecao $=24 \&$ IdTipoNoticia $=7 \&$ cientifico $=\& n$ oticias $=\& i d m e n u=$

Sata Y, Head GA, Denton K, May CN, Schlaich MP. Role of the sympathetic nervous system and its modulation in renal hypertension. Front Med (Lausanne). 2018; 29(5):82. http:// dx.doi.org/10.3389/fmed.2018.00082. PMid:29651418.

Seravalle G, Mancia G, Grassi G. Sympathetic nervous system, sleep, and hypertension. Curr Hypertens Rep. 2018; 20(9):74. http://dx.doi.org/10.1007/s11906-018-0874-y. PMid:29980938. 
Shacklock M. Biomechanics of the nervous system: breig revisited. Australia: Neurodynamic Solutions; 2007.

Silveira APC, Silva BS, Almeida MB. Acute responses from heart rate variability to exercise. EFDeportes. [Internet]. 2012 [cited 2018 Feb 10]; 16(164):1. Available from: http://www. efdeportes.com/efd164/variabilidade-da-frequencia-cardiacaao-exercicio.htm

Slater H, Vicenzino B, Wright B. Sympathetic slump: the effects of a novel manual therapy technique on peripheral sympathetic nervous system function. J Manual Manip Ther. 1994; 2(4):156-62. http://dx.doi.org/10.1179/jmt.1994.2.4.156.

Sterling M, Jull G, Wright A. Cervical mobilisation: concurrent effects on pain, sympathetic nervous system activity and motor activity. Man Ther. 2001; 6(2):72-81. http://dx.doi.org/10.1054/ math.2000.0378. PMid:11414776.

Task Force of the European Society of Cardiology, North American Society of Pacing and Electrophysiology. Heart rate variability: standards of measurement, physiological interpretation, and clinical use. Eur Heart J. 1996; 17(3):35481. PMID:873721.

Vanderlei LCM, Pastre CM, Hoshi RA, Carvalho TD, Godoy MF. Basic notions of heart rate variability and its clinical applicability. Rev Bras Cir Cardiovasc. 2009; 24(2):205-
17. http://dx.doi.org/10.1590/S0102-76382009000200018. PMid:19768301.

Vicenzino B, Cartwright T, Collins D, Wright A. Cardiovascular and respiratory changes produced by lateral glide mobilization of the cervical spine. Man Ther. 1998; 3(2):67-71. http://dx.doi. org/10.1016/S1356-689X(98)80020-9.

Vicenzino B, Collins D, Wright T. Sudomotor changes induced by neural mobilisation techniques in asymptomatic subjects. J Manual Manip Ther. 1994; 2(2):66-74. http://dx.doi.org/10.1179/ jmt.1994.2.2.66.

Vieira S, Felix ACS, Quitério RJ. Heart rate variability and maximum workload reached in the dynamic physical exertion test in elderly men. Rev Bras Med Esporte. 2012; 18(6):37780. http://dx.doi.org/10.1590/S1517-86922012000600006.

Wallen MB, Hasson D, Theorell T, Canlon B, Osika W. Possibilities and limitations of the polar RS800 in measuring heart rate variability at rest. Eur J Appl Physiol. 2012; 112(3):1153-65. http://dx.doi.org/10.1007/s00421-011-2079-9. PMid:21766225.

Wazen GLL, Gregório ML, Kemp AH, Godoy MF. Heart rate variability in patients with bipolar disorder: from mania to euthymia. J Psych Res. 2018; 99:33-8. http://dx.doi.org/10.1016/j. jpsychires.2018.01.008. PMid:29407285.v 